\title{
The effect of link-length and vertex angle on mesh generation and pattern flattening for virtual clothing
}

\author{
Abu Sadat Muhammd Sayem ${ }^{\mathrm{a}}$, Nick Clarke ${ }^{\mathrm{b}}$, Richard Kennon ${ }^{\mathrm{b}}$ and Steve Hayes ${ }^{\mathrm{b}}$ \\ ${ }^{a}$ Department of Apparel, Hollings Faculty, Manchester Metropolitan University, Righton \\ Building, Cavendish Street, Manchester, M15 6BG, UK \\ ${ }^{b}$ The School of Materials, The University of Manchester, Oxford Road, Manchester, M13 \\ $9 P L, U K$
}

\begin{abstract}
Purpose - The purpose of this paper is to identify optimum operating parameters, namely link-length and vertex angle, for producing virtual clothing prototypes for the purpose of pattern flattening.

Design/methodology/approach - Commercially available physically-based simulation and flattening engines were utilised to carry out the computational part of this study. Two separately developed 3D garment templates were used for the creation of virtual garments in the form of a triangulated mesh and later for pattern unwrapping by taking differential link-lengths and vertex angles into account to ascertain their effects on the mesh quality and on the ultimate pattern flattening process.
\end{abstract}

Findings - It has been found that a link-length between 10 and $15 \mathrm{~mm}$ and a vertex angle between $120^{\circ}$ and $160^{\circ}$ are optimum for the virtual clothing prototyping process.

Practical Implications - The findings of this study can universally be applied to simplify the tasks of virtual clothing prototyping and pattern unwrapping using commercial software packages.

Originality/Value - Previously, there has not been any guidance available for the selection of specific operational parameters to promote 3D garment design.

Key words Virtual clothing, pattern flattening, 3D garment template 


\section{Introduction}

"3D to $2 \mathrm{D}$ pattern unwrapping" is an emerging technique for producing pattern for clothing manufacture (Sayem et al. 2010). This technique incorporates the creation of a virtual garment prototype on a $3 \mathrm{D}$ platform (a virtual manikin or product specific 3D template) using a computer mouse or stylus, followed by the automatic generation of 2D patterns by unwrapping or flattening the 3D design with help of a flattening engine (McCartney et al., 2000; Kim \& Kang, 2002; Wang et al. 2002; Wang, Wang \& Yuen, 2002; Sayem, 2004; Petrak et al. , 2006; Decaudin et al., 2006; Kim and Petrak, 2007; Fang \& Ding, 2008 and Sayem et al. 2012, 2014a, b). For the purpose of pattern unwrapping, a virtual garment prototype is usually developed as a localised layer known as a "region" created on or above the surface of a virtual manikin or 3D template available within 3D CAD systems (Sayem, 2012). Technically, a region is a surface produced in form of a triangular mesh limited by one or more boundaries. Using appropriate tools for drawing region curves and for creating the region from curves, a virtual garment can be produced on the 3D virtual templates as demonstrated in Roedel (2008) and Sayem et al. (2012, 2014a,b). Two modes for implementing region creation are commonly followed within 3D CAD systems, namely: "Link-length-based region creation" and "Curvature-based region creation". The former is commonly recommended by the $\mathrm{CAD}$ software suppliers for use in flat pattern extraction for the apparel industry and for car seat making in the automotive industry (DCTT, n.d.).

The control parameters used in the link-length mode of region creation are the link-length itself and the vertex angle formed by the links in each triangle within the mesh. The link indicates the edge of each triangle in a triangular mesh formed from a multitude of triangles, but the selected vertex angle only controls the angle formed at the corner points on the mesh boundary. These parameters play a vital role in the triangulation process during mesh generation and also in the conversion process of transforming a $3 \mathrm{D}$ surface into 2D flat surface using a flattening engine. The size and shape of the triangles forming the mesh effectively control the resolution of the "wire netting" surface and thus determine the smoothness and precision of the pattern pieces unwrapped from it. Presently there are no guidelines available in published literature to assist in the selection of link-length and vertex angle for virtual clothing prototyping and pattern flattening. This research discusses the influence of varying link-lengths and vertex angles on the 
quality of the generated mesh surface and on the flattened pattern pieces as well as on the speed of mesh generation and pattern flattening processes.

\section{Methodology}

In order to ascertain the effect of technical parameters on mesh generation and pattern flattening for virtual clothing, it is essential to first prepare the appropriate platforms, on which the desired virtual clothing can be developed. As a part of it, two resizable 3D templates, one for men's shirts and another for men's trousers, were developed from bodyscan data. Point-cloud data from an adult male subject was captured by a modern white-light-based 3D body-scanning system (NX-16 from $\mathrm{TC}^{2}$, USA) and further utilised as the basic input for creating the outerwear templates. After primary processing by the NX-16 proprietary software, the scan-data in '.obj' format were imported into a reverse engineering CAD system "Geomagic Studio 11". This was further processed into a digital CAD model in '.igs' file format, from which a set of sectional curves representative of anthropometric size parameters was extracted. These sectional curves were then imported into Lectra 3D CAD system DesignConcept TexTech (DCTT) and modified to reproduce the required profile upon which to create items of men's outerwear in $3 \mathrm{D}$ form. The curves were made symmetrical, as required, before scaling to impart resizability. Using a geometric modelling technique, a new surface was generated out of these resizable curves to form the required 3D outerwear templates. The complete workflow is presented in the Figure 1.

In order to make it resizable, a shirt template was scaled with twelve size parameters (seven for the body and five for the sleeves) represented by construction curves. The scaling process, as described in Sayem et al. (2012, 2014a,b), forms the basis of automatic 3D grading. The value of the size parameters i.e. the length of the scaled curves can be altered individually or in group (representing the arm, or the torso for instance) and this procedure may be invoked whenever it is deemed to be necessary, by the designer or by a pattern technician. A set of size-databases for men's shirts from size 37 to size 45 was developed in MS Excel worksheets by adapting the standard shirt measurement available in Aldrich (1990), and the 3D template was programmed to be able to use any preferred size parameters from Excel databases for the purpose of automatic grading into any required size and fit. 
Similarly, a resizable trouser template was made based on eleven size parameters including nine girth measurements and two linear measurements (body rise and inseam). A set of size databases for men's trousers from size 74 to size 110 was developed by adapting the standard trousers measurement available in Aldrich (1990). As before these control parameters were stored in an Excel database.

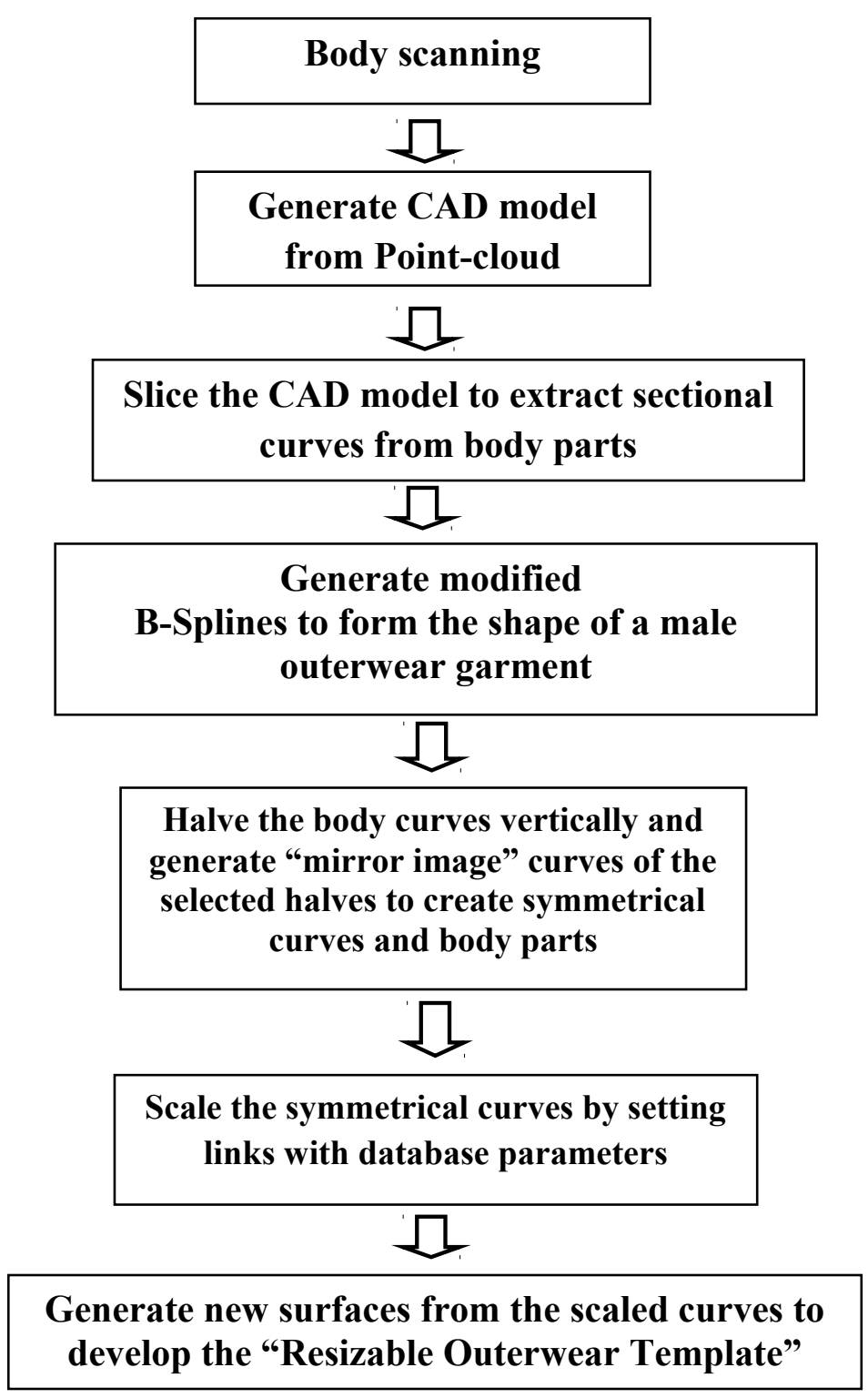

Figure 1 Workflow for Resizable Outerwear Template

The resizable 3D templates for men's shirts and trousers used in this work are presented in Figures 2 and 3, and were used for developing virtual garments and for pattern flattening. A commercial 3D CAD system with physically based simulation and flattening engines has been used. During the link-length based region creation, different 
combinations of link-lengths and vertex angles were tried to ascertain their effects on the mesh quality and on the ultimate pattern flattening process. The experimental part of this research work was performed on computers with the following specifications:

System A: Intel (R) Core TM 2 Duo processors (E7400@2.80 GHz, 2.79 GHz); 4 GB of RAM; Microsoft XP Professional Version 2002 (32-bit Operating System);

System B: Intel ${ }^{\circledR}$ Core $^{\mathrm{TM}}$ i7 processor, Memory 16GB DDR3L RAM, Graphics NVIDIA ${ }^{\circledR}$ GTX-860M with 4G VRAM; Windows 8.1 Operating System.

Most of the experiments were carried out in system A, however where system A failed to handle the computation, system B was used to double check those situations.
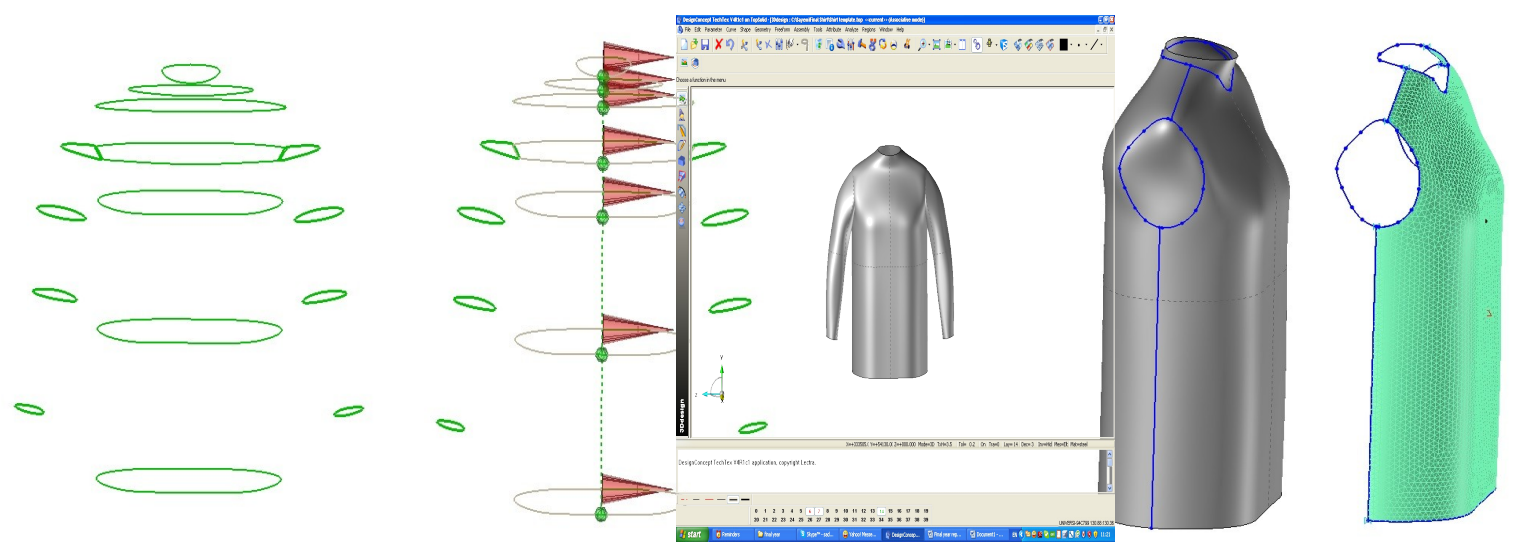

a) Generation of 3D Shirt Template from scaled sectional Curves

b) Outlines of men's shirt drawn on the a) 3D Shirt Templc template and Virtual shirt as triangulated zmesh surface

Figure 2. 3D Shirt Template and Triangulated 3D Mesh Structure

Figure 1 The Shirt Template

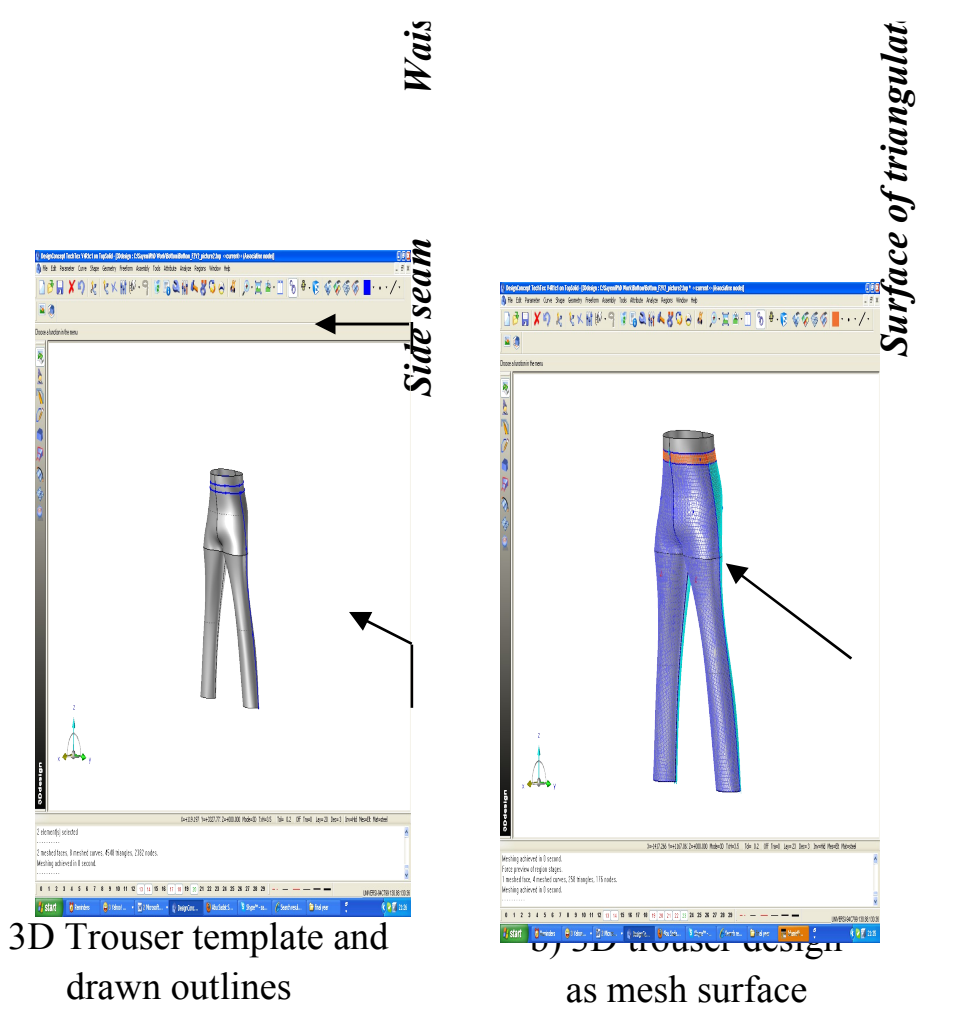

Figure 3. 3D Trouser Template and 3D Trouser Mesh 


\section{Experimental Work}

\subsection{Drawing in 3D}

The newly developed 3D templates can work as 3D drawing boards as they are built with interactive CAD surfaces. Before drawing product outlines, the size and shape of the $3 \mathrm{D}$ templates were adjusted to correspond to size 41 for the shirt and size 90 for the trousers by linking the appropriate Excel size databases developed beforehand. Tools for drawing the 'region curve' were utilised to draw the outlines of a men's shirt and a trouser design on the relevant $3 \mathrm{D}$ design platforms as depicted in figures $2 \mathrm{~b}$ and $3 \mathrm{a}$. It may be observed that the definitions of side seams, arm-holes, shoulder seams, neck and inseam for the sleeve are required to produce the virtual shirt. It also may be observed that the definitions for the waist band and the outer side seam are the only ones required to produce a design for a pair of trousers on this $3 \mathrm{D}$ trouser template.

\subsection{Mesh generation}

Once a drawing has been completed, an area of triangulated mesh is created on the templates following the link length-based region creation mode. This triangulated shape thus forms the virtual clothing. This process required the selection of the link-length and vertex angle. To check the effect of differential vertex angles, triangulated meshes were generated keeping the link-length as $100 \mathrm{~mm}, 50 \mathrm{~mm}$ and $10 \mathrm{~mm}$ progressively and were tested for vertex angles from $10^{\circ}$ to $170^{\circ}$ at every $10^{\circ}$ interval. To check the effect of variable link-lengths, the shirt and trouser patterns were generated using different linklengths between $1 \mathrm{~mm}$ and $100 \mathrm{~mm}$ and the required time and quality of the mesh were examined, as can be seen in Tables $1 \& 2$.

\subsection{Pattern flattening}

In order to convert the $3 \mathrm{D}$ designs for the shirt and trousers into flat pattern pieces, the region-flattening tool avilable in the CAD system was used. The flattening operation involves two steps: first, the selection of the region to be flattened, and second, the selection of various flattening options that could be coupled to the flattening parameters. In order to maintain the dimensional integrity of the flat pattern pieces, the option "Match edge lengths" was selected. The flattening tool used in the work considers the 
geometric constraint of the shape, but does not incorporate any material properties for the textile fabrics. The process is comparable to the flattening of a network of springs whose stability is obtained through an even distribution of the internal energy. It is an iterative process which proceeds layer by layer beginning from the starting point of the flattening process. The flattening sequence may be subject to automatic and numerical control. The automatic control allows the flattening algorithm to run until balance is reached. This option has been selected for pattern flattening throughout this research work. The flattening times for every combination of vertex angle and link-length were noted.

\section{Results \& Discussion}

\subsection{Effect of link length}

The size and number of triangles in a mesh structure plays avital role in defining its surface quality. When the size of the triangles is big, the number of triangles is low, so computer processing effort is modest but the generated surface cannot follow the geometry of the 3D template, and drawn boundary lines, as it is evident in Figure 4a. The link-length influences the size and number of triangles in the manipulation. When the mesh was generated at a $100 \mathrm{~mm}$ link-length, the numbers of triangles were 85 and 46 respectively for the shirt and the trouser front panels. As the size of link-length increases, as presented in Tables $1 \& 2$ and Figures $6 \& 7$, the number of triangles in mesh increases and the size of triangles decreases, as can also be seen in Figures $4 \& 5$. When the size of the triangles is small and the number is high, the mesh structure is found to have adopted the shape of the drawn outlines and the geometry of $3 \mathrm{D}$ templates accurately, as shown in Figures 4c \& 5c. Based on this finding it can be stated that linklength directly influences the quality of the generated mesh surface and the flattened pattern pieces. It was also found that the speed of mesh generation and pattern flattening were directly affected by the link-length. Tables 1 and 2 present the effects of the choice of link-length on the meshes generated for the shirt and the trouser templates respectively. For this part, the vertex angle was kept constant at $130^{\circ}$ as it had been found to produce optimal results and this is further detailed in the next section. In both cases, the smaller the link-length of the triangles in the mesh structures, the higher the mesh surface area, and the lower the mesh generation and pattern flattening speeds. In computer system A, the mesh generation time is below 1 second when the link-length is 
above $15 \mathrm{~mm}$. However, the quality of the generated mesh surface was relatively poor. For the shirt front pattern piece as shown in Figure 4, the generated mesh surface did not follow the contours of the drawn outlines correctly. It may be observed, particularly in the neck curve and the armhole curve areas, that the generated surface hardly followed the geometry of the drawn outline at all. In the case of the front panel of a pair of trousers, which can be seen in Figure 5, the surface geometry was not correctly reproduced when the link length was set as $100 \mathrm{~mm}$.

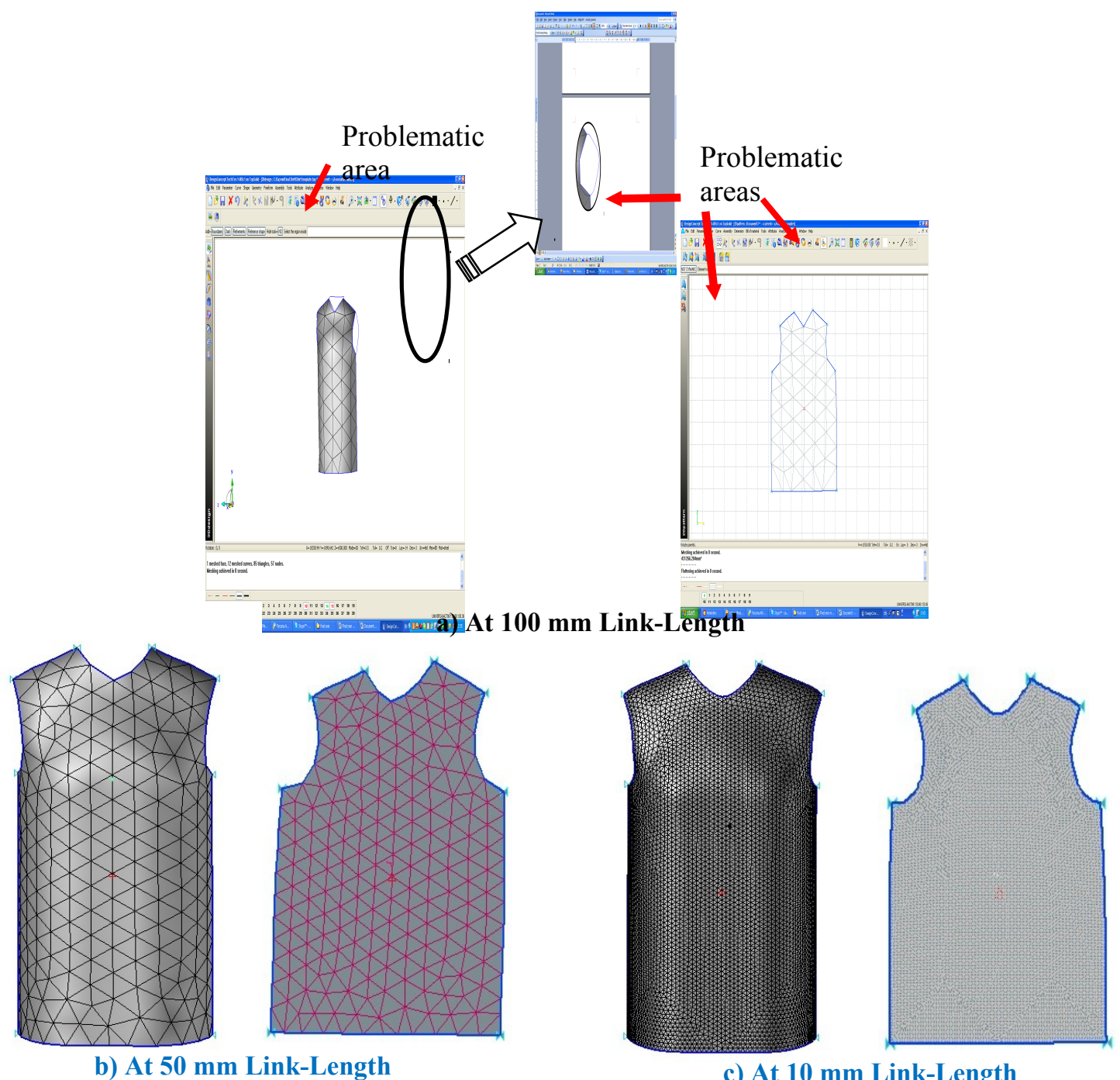

Figure 4. Mesh Surface and Flattened Patterns of a shirt panel at different Link-Lengths 

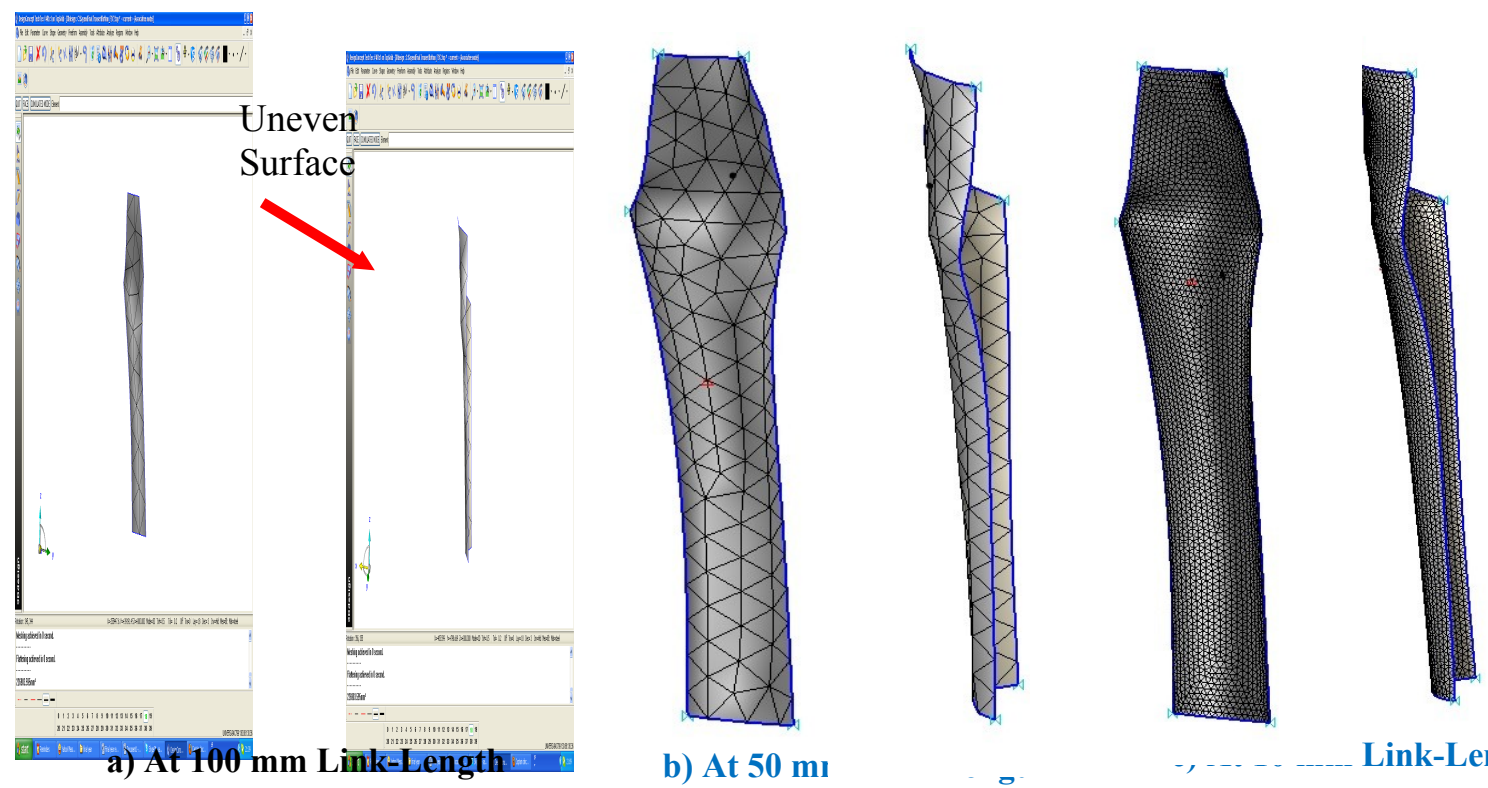

b) At $50 \mathrm{ml}$

Link-Length

Figure 5. Mesh Structure Pattern of Trouser front at different Link lengths

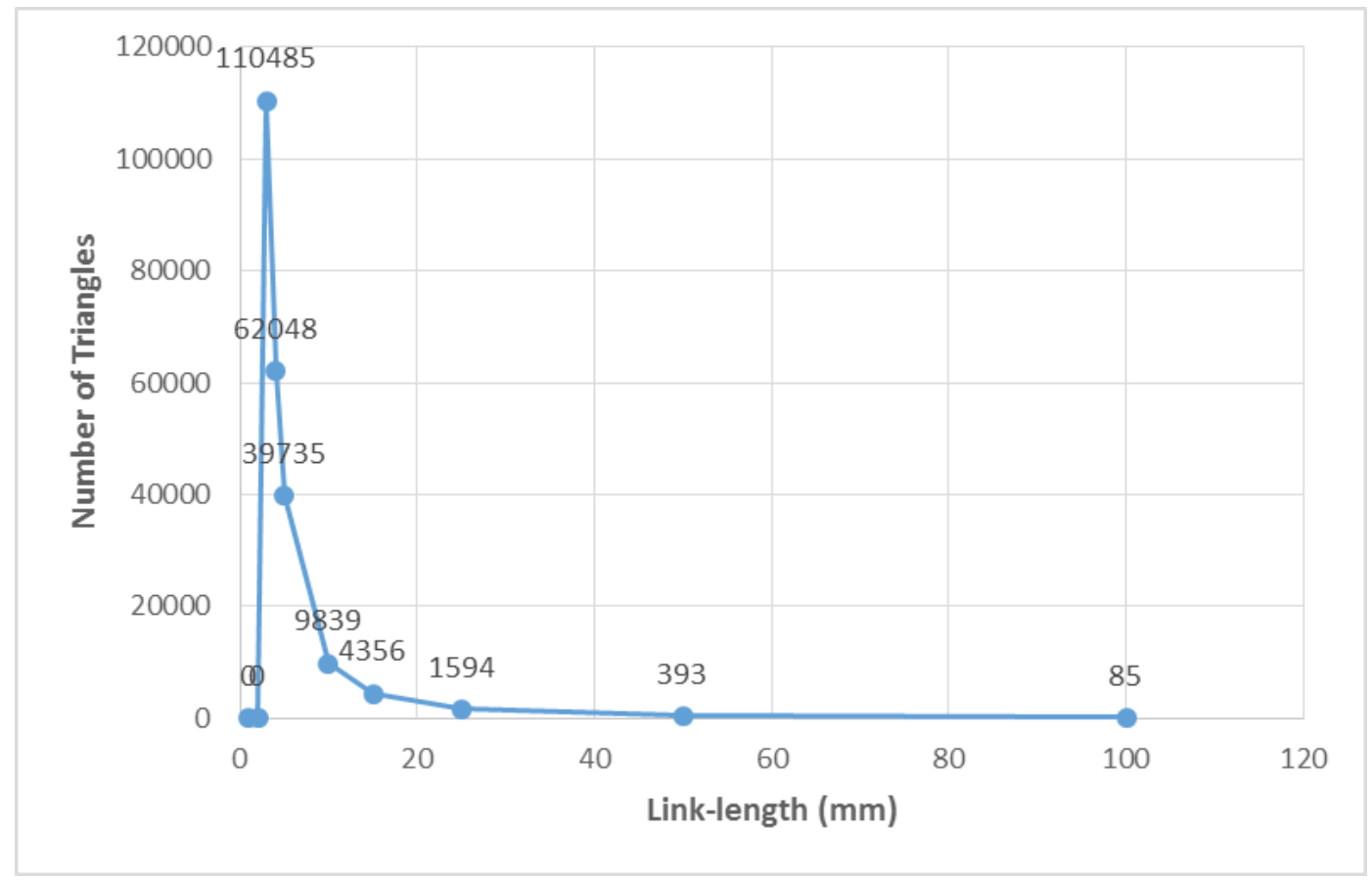

Figure 6. Effect of Link-length on the Number of Triangles in the Shirt Panel 


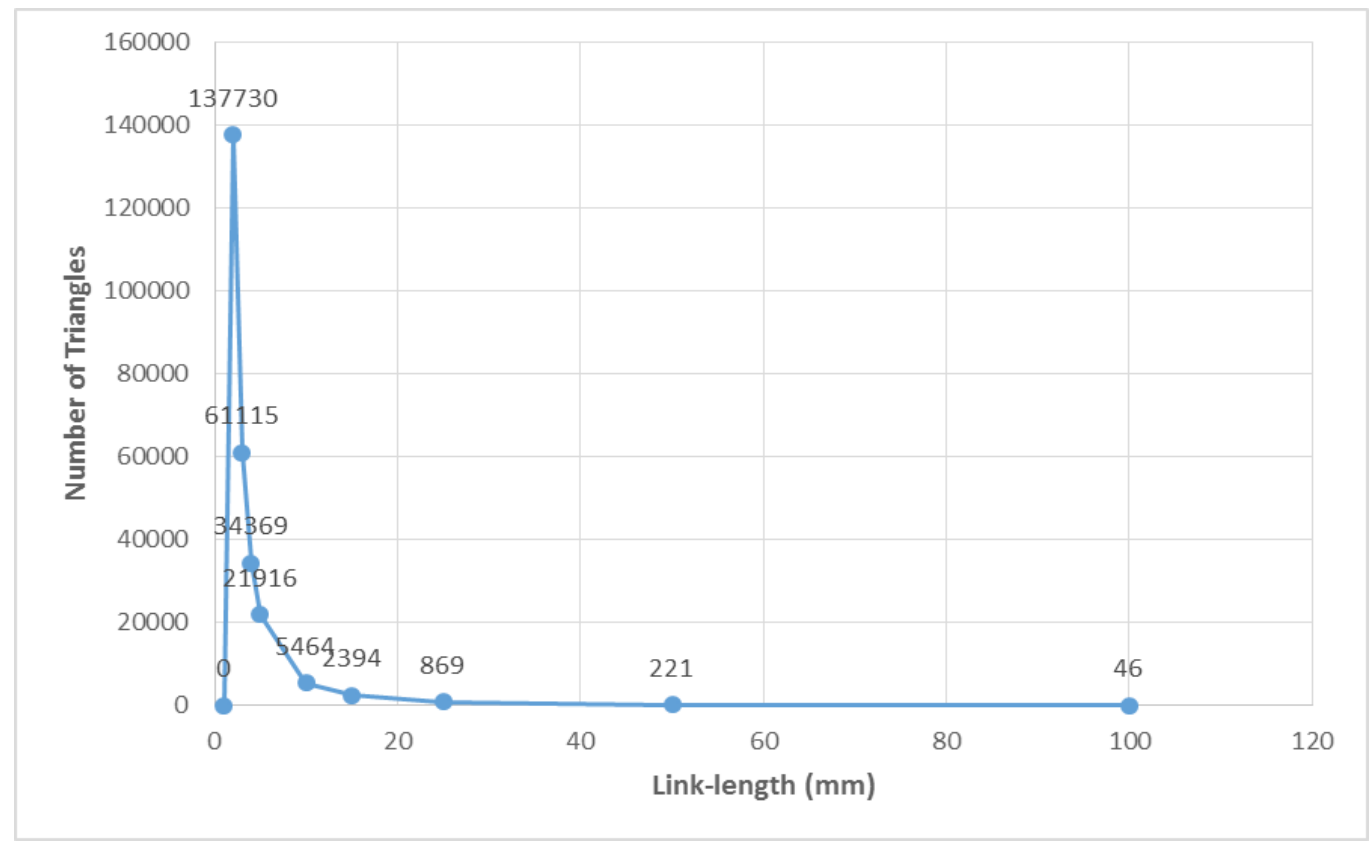

Figure 7. Effect of Link-length on the Number of Triangles in the Trouser Panel

When the link-length was defined as $5 \mathrm{~mm}$ or smaller, both the mesh generation and the pattern flattening processes were found to be very slow. In particular, the total flattening times required in these cases were very high and could not be considered feasible for clothing designers. In system A, The flattening engine did not work at all when the linklength was set below $4 \mathrm{~mm}$ for shirts and $3 \mathrm{~mm}$ for trouser designs respectively. With a link-length below $3 \mathrm{~mm}$ for shirts and below $2 \mathrm{~mm}$ for trouser designs, the mesh generation engine was found to be unable to handle the large number of calculations. These situations were double-tested in system B and the same outcomes were experienced.

Table 1: Effect of Link-Length on Pattern Generation of Shirt Front Panel

\begin{tabular}{|c|c|c|c|c|c|c|}
\hline \multirow{11}{*}{ 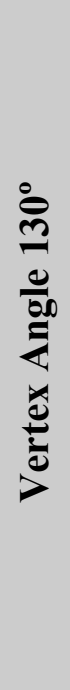 } & $\begin{array}{c}\text { Link } \\
\text { Length } \\
\text { (mm) }\end{array}$ & $\begin{array}{c}\text { Mesh } \\
\text { Generation }\end{array}$ & $\begin{array}{c}\text { Number } \\
\text { of } \\
\text { Triangles }\end{array}$ & $\begin{array}{l}\text { Meshing } \\
\text { Time } \\
\text { (second) }\end{array}$ & $\begin{array}{c}\text { Mesh } \\
\text { Surface } \\
\left(\mathrm{mm}^{2}\right)\end{array}$ & $\begin{array}{c}\text { Flattening } \\
\text { Time } \\
\text { (second) }\end{array}$ \\
\hline & 100 & Yes & 85 & $<1$ & 431266.204 & $<1$ \\
\hline & 50 & Yes & 393 & $<1$ & 435492.934 & $<1$ \\
\hline & 25 & Yes & 1594 & $<1$ & 436543.460 & $<1$ \\
\hline & 15 & Yes & 4356 & $<1$ & 436701.373 & 13 \\
\hline & 10 & Yes & 9839 & 1 & 436753.486 & 84 \\
\hline & 5 & Yes & 39735 & 5 & 436788.155 & 1852 \\
\hline & 4 & Yes & 62048 & 8 & 436792.417 & 4358 \\
\hline & 3 & Yes & 110485 & 15 & 436795.816 & $\begin{array}{l}\text { Program } \\
\text { Collapse }\end{array}$ \\
\hline & 2 & No & 0 & - & 0 & - \\
\hline & 1 & No & 0 & - & 0 & - \\
\hline
\end{tabular}


Table 2: Effect of Link Length on Pattern Generation for Trouser Front Panel

\begin{tabular}{|c|c|c|c|c|c|c|}
\hline \multirow{11}{*}{ 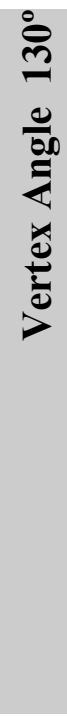 } & $\begin{array}{l}\text { Link } \\
\text { Length } \\
(\mathrm{mm})\end{array}$ & $\begin{array}{c}\text { Mesh } \\
\text { Generation }\end{array}$ & $\begin{array}{c}\text { Number } \\
\text { of } \\
\text { Triangles }\end{array}$ & $\begin{array}{l}\text { Meshing } \\
\text { Time } \\
\text { (second) }\end{array}$ & $\begin{array}{c}\text { Mesh } \\
\text { Surface } \\
\left(\mathrm{mm}^{2}\right)\end{array}$ & $\begin{array}{c}\text { Flattening } \\
\text { time } \\
\text { (second) }\end{array}$ \\
\hline & 100 & Yes & 46 & $<1$ & 226903.595 & $<1$ \\
\hline & 50 & Yes & 221 & $<1$ & 235445.804 & $<1$ \\
\hline & 25 & Yes & 869 & $<1$ & 237279.252 & $<1$ \\
\hline & 15 & Yes & 2394 & $<1$ & 237716.080 & 2 \\
\hline & 10 & Yes & 5464 & 1 & 237888.423 & 18 \\
\hline & 5 & Yes & 21916 & 2 & 237986.605 & 407 \\
\hline & 4 & Yes & 34369 & 4 & 237998.725 & 850 \\
\hline & 3 & Yes & 61115 & 7 & 238008.382 & 2774 \\
\hline & 2 & Yes & 137730 & 20 & 238015.209 & $\begin{array}{l}\text { Program } \\
\text { Collapse }\end{array}$ \\
\hline & 1 & No & 0 & - & 0 & - \\
\hline
\end{tabular}

The optimum link-length, considering the quality of the mesh surface and the flattened pattern pieces and the speeds of mesh generation and pattern flattening, was found to be between $10 \mathrm{~mm}$ and $15 \mathrm{~mm}$ for both shirt and trouser designs.

\subsection{Effect of vertex angle}

From the garment manufacturing viewpoint, it is often necessary to measure the edges of the virtual garments and flattened pattern pieces, as illustrated in Figures $9 \& 10$. For the shirt panel (in Figure 9), there are eight edges and for the trouser front panel (in Figure 10), there are five edges, which should be measurable. It has been found that the vertex angle does not influence the quality of the mesh surface, rather it only influences the number of individual curves formed along the boundary line of the mesh surface and the flattened pattern pieces. It can be seen from Table 3 that when a vertex angle between $130^{\circ}$ and $160^{\circ}$ was selected having a link-length of $100 \mathrm{~mm}$, the boundary line was found to be segmented at every available corner point. When the link-length was $50 \mathrm{~mm}$ and $10 \mathrm{~mm}$, it was also found to have separated eight edges in the mesh pattern and in flattened pattern pieces with a vertex angle $120^{\circ}$ and above, as can be seen the table 3 and Figures $8 \& 9$. This helped to measure each of the relevant edges of the pattern individually, such as the neckline, shoulder, armhole curve and side seams. This is very useful for the clothing industry as it allows checking of the dimensional quality of the flattened pattern pieces. Figures 9 and 10 illustrate the length analysis of the edges of the flattened pattern pieces when the vertex angle was maintained at $120^{\circ}$ and the links were at an optimal10mm length. 
However, when a vertex angle below $120^{\circ}$ was selected, the boundary line was found not to be segmented at every corner point, which did not allow individual measurement of the pattern edges. This is clearly shown in Figure 8. For the trouser panel, any vertex angle above $160^{\circ}$ and up to $180^{\circ}$ produced too many segmented points and this also was unhelpful from the pattern designing point of view.

Table 3 Effect of Vertex Angle on the Number of Triangles in the Shirt Panel

\begin{tabular}{|c|c|c|c|c|c|c|}
\hline \multirow{2}{*}{$\begin{array}{c}\text { Vertex } \\
\text { Angle }\left({ }^{\circ}\right)\end{array}$} & \multicolumn{2}{|c|}{ Link-length $100 \mathrm{~mm}$} & \multicolumn{2}{|c|}{ Link-length $50 \mathrm{~mm}$} & \multicolumn{2}{|c|}{ Link-length $10 \mathrm{~mm}$} \\
\hline & $\begin{array}{c}\text { No. of } \\
\text { Segments }\end{array}$ & $\begin{array}{c}\text { No. of } \\
\text { Triangles }\end{array}$ & $\begin{array}{c}\text { No. of } \\
\text { Segments }\end{array}$ & $\begin{array}{c}\text { No. of } \\
\text { Triangles }\end{array}$ & $\begin{array}{c}\text { No. of } \\
\text { Segments }\end{array}$ & $\begin{array}{c}\text { No. of } \\
\text { Triangles }\end{array}$ \\
\hline 170 & 8 & 85 & 8 & 393 & 8 & 9839 \\
\hline 160 & 8 & 85 & 8 & 393 & 8 & 9839 \\
\hline 150 & 8 & 85 & 8 & 393 & 8 & 9839 \\
\hline 140 & 8 & 85 & 8 & 393 & 8 & 9839 \\
\hline 130 & 8 & 85 & 8 & 393 & 8 & 9839 \\
\hline 120 & 6 & 85 & 8 & 393 & 8 & 9839 \\
\hline 110 & 4 & 85 & 7 & 393 & 8 & 9839 \\
\hline 100 & 2 & 85 & 4 & 393 & 7 & 9839 \\
\hline 90 & 2 & 85 & 2 & 393 & 3 & 9839 \\
\hline 80 & 1 & 85 & 1 & 393 & 1 & 9839 \\
\hline 70 & 1 & 85 & 1 & 393 & 1 & 9839 \\
\hline 60 & 1 & 85 & 1 & 393 & 1 & 9839 \\
\hline 50 & 1 & 85 & 1 & 393 & 1 & 9839 \\
\hline 40 & 1 & 85 & 1 & 393 & 1 & 9839 \\
\hline 30 & 1 & 85 & 1 & 393 & 1 & 9839 \\
\hline 20 & 1 & 85 & 1 & 393 & 1 & 9839 \\
\hline 10 & 1 & 85 & 1 & 393 & 1 & 9839 \\
\hline
\end{tabular}


Table 4 Effect of Vertex Angle on the Number of Triangles of Trouser Panel

\begin{tabular}{|c|c|c|c|c|c|c|}
\hline \multirow{2}{*}{$\begin{array}{c}\text { Vertex } \\
\text { Angle }\left({ }^{\circ}\right)\end{array}$} & \multicolumn{2}{|c|}{ Link-length $100 \mathrm{~mm}$} & \multicolumn{2}{|c|}{ Link-length $50 \mathrm{~mm}$} & \multicolumn{2}{|c|}{ Link-length $10 \mathrm{~mm}$} \\
\hline & $\begin{array}{c}\text { No. of } \\
\text { Segments }\end{array}$ & $\begin{array}{c}\text { No. of } \\
\text { Triangles }\end{array}$ & $\begin{array}{c}\text { No. of } \\
\text { Segments }\end{array}$ & $\begin{array}{c}\text { No. of } \\
\text { Triangles }\end{array}$ & $\begin{array}{c}\text { No. of } \\
\text { Segments }\end{array}$ & $\begin{array}{c}\text { No. of } \\
\text { Triangles }\end{array}$ \\
\hline 170 & 6 & 46 & 6 & 221 & 6 & 5464 \\
\hline 160 & 6 & 46 & 6 & 221 & 5 & 5464 \\
\hline 150 & 5 & 46 & 5 & 221 & 5 & 5464 \\
\hline 140 & 5 & 46 & 5 & 221 & 5 & 5464 \\
\hline 130 & 5 & 46 & 5 & 221 & 5 & 5464 \\
\hline 120 & 4 & 46 & 5 & 221 & 5 & 5464 \\
\hline 110 & 4 & 46 & 4 & 221 & 5 & 5464 \\
\hline 100 & 3 & 46 & 3 & 221 & 5 & 5464 \\
\hline 90 & 2 & 46 & 2 & 221 & 5 & 5464 \\
\hline 80 & 1 & 46 & 1 & 221 & 3 & 5464 \\
\hline 70 & 1 & 46 & 1 & 221 & 1 & 5464 \\
\hline 60 & 1 & 46 & 1 & 221 & 1 & 5464 \\
\hline 50 & 1 & 46 & 1 & 221 & 1 & 5464 \\
\hline 40 & 1 & 46 & 1 & 221 & 1 & 5464 \\
\hline 30 & 1 & 46 & 1 & 221 & 1 & 5464 \\
\hline 20 & 1 & 46 & 1 & 221 & 1 & 5464 \\
\hline 10 & 1 & 46 & 1 & 221 & 1 & 5464 \\
\hline
\end{tabular}

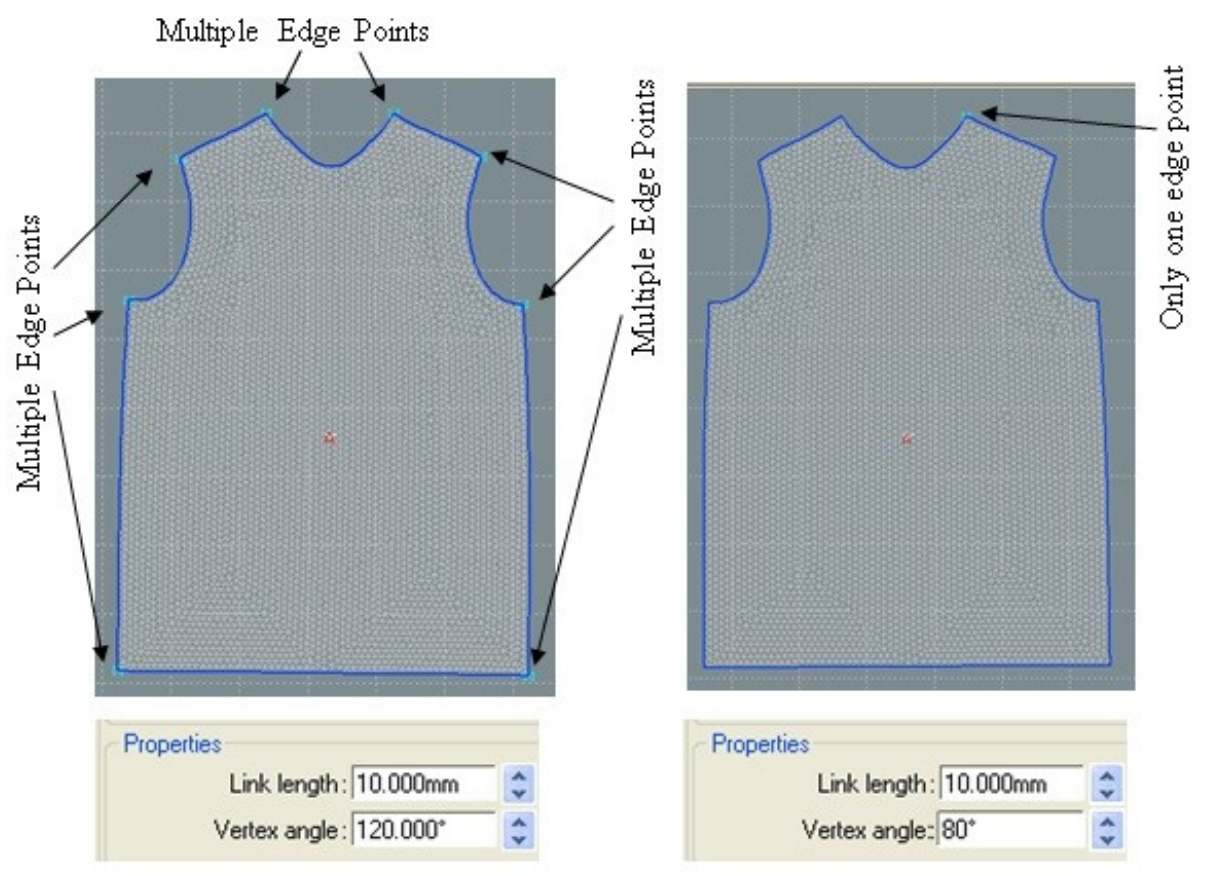

Figure 8. Effect of Vertex Angle on Generated Pattern 


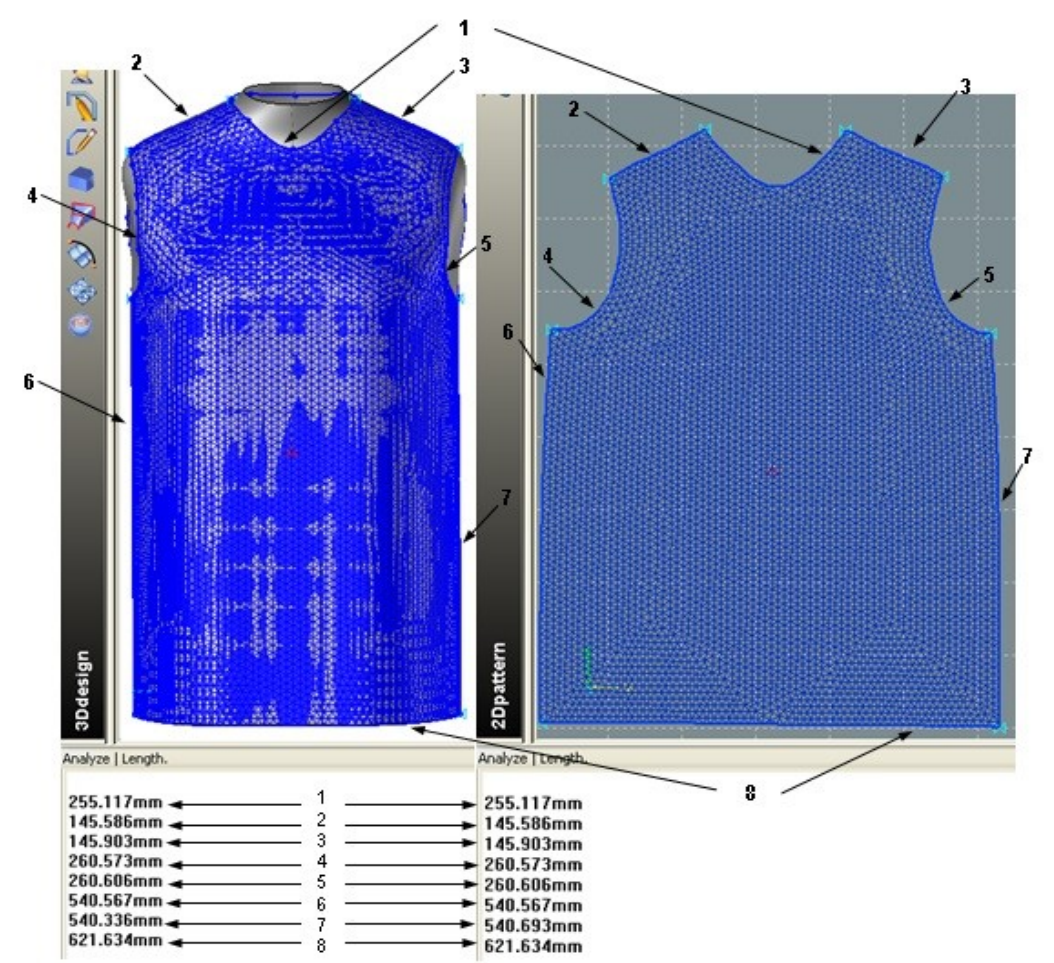

Figure 9. Measurements of Eadge Lengths of Flattened Shirt Pattern (Size 41)

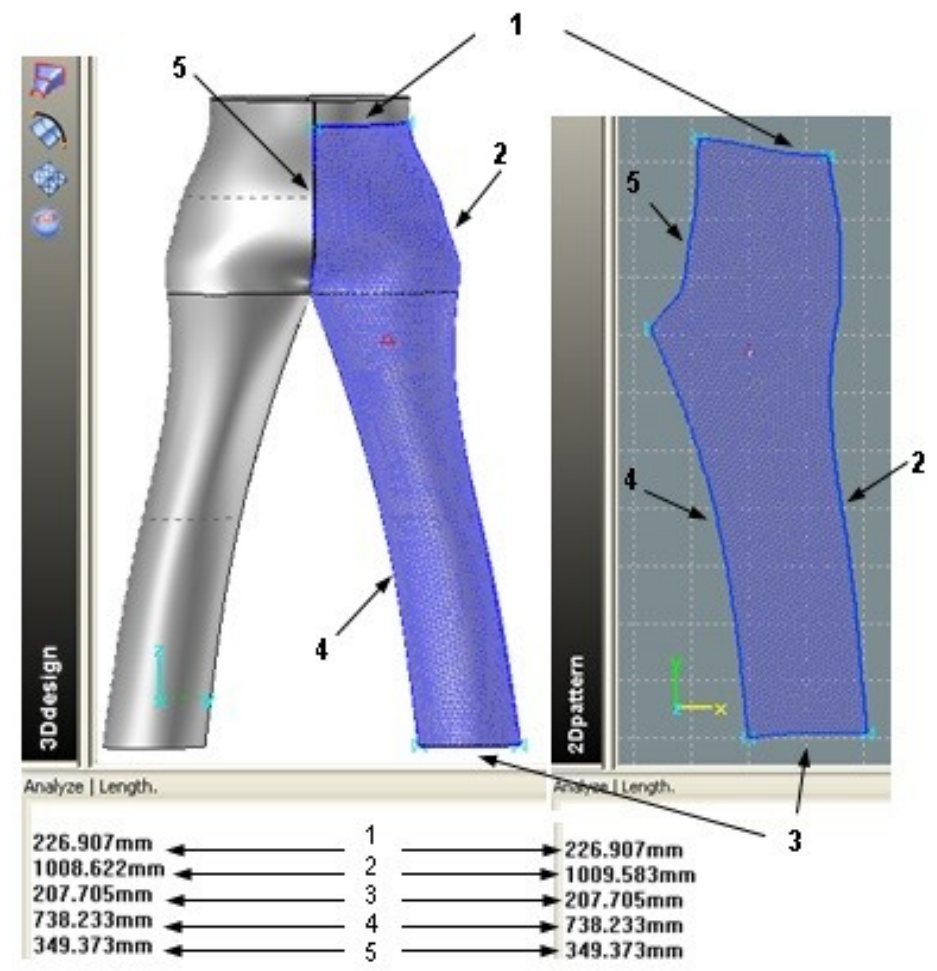

5. Conı Figure 10. Measurements of Eadge Lengths of Flattened Trouser Pattern (Size 90) 
This research has investigated the effects of variable link-lengths and vertex angles on the mesh quality and on the mesh creation and flattening times during virtual clothing prototyping and flat pattern generation. It has been found that the bigger the link-length selected for a mesh structure, the smaller the mesh surface area and the higher the meshing and flattening speeds; but it has also been found that there is a commensurate deterioration in the quality of the pattern pieces. However, any link-length below $5 \mathrm{~mm}$ is technically not feasible for computers offering conventional level of processing capability. The optimum link-length has been found to be between $10 \mathrm{~mm}$ and $15 \mathrm{~mm}$. It has also been found that the vertex angle primarily influences the segmentation of the pattern boundary line but not the surface quality of the generated mesh. The optimum vertex angle for virtual clothing and pattern generation was found to lie between $120^{\circ}$ and $160^{\circ}$ when the link-length is selected between $10 \mathrm{~mm}$ and $15 \mathrm{~mm}$. This finding will be beneficial for the pattern cutters while working with virtual prototyping and surface unwrapping systems in the clothing industry and will be helpful for designers wishing to set up 3D designing facilities with a target to achieve automatic flat patterns directly from 3D designs.

\section{References}

Aldrich, W. (1990), Metric pattern cutting for menswear, $2^{\text {nd }}$ edition, Blackwell Scientific Publications, Oxford.

DCTT (n.d.), Help Menu. DesignConcept TexTech V4R1c1, Lectra, France

Decaudin, P., Julius, D., Wither, J., Boissieux, L., Sheffer, A. and Cani, M. (2006), "Virtual garments: A fully geometric approach for clothing design" EUROGRAPHICS 2006, Vol. 25 No. 3, pp. 625-634.

Fang, J. and Ding, Y. (2008), "Expert-based customized pattern-making automation: Part I. Basic patterns", International Journal of Clothing Science and Technology, Vol. 20 No. 1 , pp. $26-40$.

Kim, S.M. and Kang, T. J. (2002), "Garment pattern generation from body scan data", Computer-Aided Design, Vol. 35, pp. 611-618. 
Kim, S. and Park, C. K. (2007), "Basic garment pattern generation using geometric modelling method", International Journal of Clothing Science and Technology, Vol. 19 No. 1, pp. 7-17.

McCartney, J., Hinds, B.K., Seow, B.L. and Gong, D. (2000), "Dedicated 3D CAD for garment modelling”, Journal of Materials Processing Technology, Vol. 107, pp. 31-36.

Petrak, S., Rogale, D. and Mandekic'-Botteri, V. (2006), "Systematic representation and application of a 3D computer-aided garment construction method Part II: spatial transformation of 3D garment cut segments", International Journal of Clothing Science and Technology, Vol. 18 No. 3, pp. 188-199.

Sayem, A.S.M. (2004), Beitrag zur Entwicklung parametrischer virtueller Formkörper weiblicher Personen zur dreidimensionalen Konstruktion von körpernaher Bekleidung und Miederwaren, Masterarbeit Nr. 1275 [Study on the development of parametric virtual female bodies for the three dimensional construction of close-fitting and foundation garments]. Thesis (MSc.), Technische Universitaet Dresden (TU Dresden), Germany.

Sayem, A. S. M., Kennon, R., and Clarke, N. (2010), "3D CAD systems for the clothing industry" International Journal of Fashion Design, Technology and Education, Vol. 3 No. 2, pp. 45-53.

Sayem, A. S. M., Kennon, R., and Clarke, N. (2012), "Resizable trouser template for virtual design and pattern flattening", International Journal of Fashion Design, Technology and Education, Vol. 5 No. 1, pp. 55-65,

URL: http://dx.doi.org/10.1080/17543266.2011.614963

Sayem, A. S. M., Kennon, R., and Clarke, N. (2014a), "3D Grading and Pattern Unwrapping Technique for Loose-fitting Shirt, Part 1: Resizable Design Template", Journal of Textile and Apparel, Technology and Management, Vol. 8 No. 4, [Online] North Carolina State University, USA, URL:

http://ojs.cnr.ncsu.edu/index.php/JTATM/article/view/5145 [Accessed 31 March 2015] 
Sayem, A. S. M., Kennon, R., and Clarke, N. (2014b), "3D Grading and Pattern Unwrapping Technique for Loose-fitting Shirt, Part 2: Functionality", Journal of Textile and Apparel, Technology and Management, Vol. 8 No. 4, [Online] North Carolina State University, USA, URL:

http://ojs.cnr.ncsu.edu/index.php/JTATM/article/view/5147 [Accessed 31 March 2015]

Wang, C.C.L; Smith, S. S. and Yuen, M.M.F. (2002), "Surface flattening based on energy model”, Computer-Aided Design, Vol. 34, pp. 823-833.

Wang, C.C.L.; Wang, Y. and Yuen, M.M.F. (2002), "Feature based 3D garment design through 2D sketches", Computer-Aided Design, Vol. 35, pp. 659-672. 